\title{
Stereoselective Nanocarbon Imides Featuring 12-fold [5]helicenes
}

\author{
Guogang Liu, ${ }^{*}{ }^{\dagger}$ Marvin Nyenhuis, ${ }^{\perp}$ Dong Meng, ${ }^{\star}$ Nikos L. Doltsinis, ${ }^{\perp}$ Yan Li, ${ }^{*}$ Zhaohui Wang, ${ }^{*}$ and He \\ $\operatorname{Tian}^{\dagger}$
}

${ }^{\dagger}$ Key Laboratory for Advanced Materials and Joint International Research Laboratory of Precision Chemistry and Molecular Engineering, Feringa Nobel Prize Scientist Joint Research Center, Frontiers Science Center for Materiobiology and Dynamic Chemistry, Institute of Fine Chemicals, School of Chemistry and Molecular Engineering, East China University of Science and Technology, Shanghai 200237, China

${ }^{\ddagger}$ Key Laboratory of Organic Optoelectronics and Molecular Engineering, Department of Chemistry, Tsinghua University, Beijing 100084, China

${ }^{\S}$ School of Chemistry, Beihang University, Beijing 100191, China

${ }^{\perp}$ Institute for Solid State Theory and Center for Multiscale Theory \& Computation, University of Münster, Wilhelm-KlemmStr. 10, 48149 Münster, Germany

\begin{abstract}
Despite the great progress in research on chiral molecular nanocarbons containing multiple helicenes, controlling the stereoselectivity is still a major challenge, especially when attempting to increase the number of helicene moieties. Herein, a novel molecular nanocarbon imides composed of $\mathrm{C}_{204}$ skeleton and eighteen imide groups was successfully synthesized via an inside-out ring closing strategy involving repeated Suzuki-Miyaura coupling for $\mathrm{C}-\mathrm{C}$ bond formation and photocyclic aromatization. Because of the presence of quad-core twelvefold [5]helicenes, there are, in theory, more than one hundred stereoisomers. However, only one pair of stereoisomers with $D_{3}$ symmetry was observed. Despite the large and rigid skeleton, the $(3 \mathrm{M}, 3 \mathrm{M}, 3 \mathrm{M}, 3 \mathrm{M})+(3 \mathrm{P}, 3 \mathrm{P}, 3 \mathrm{P}, 3 \mathrm{P})$ enantiomers were successfully separated by chiral HPLC, and the chiroptical properties were investigated by CD spectroscopy.
\end{abstract}

\section{INTRODUCTION}

In recent years, the emerging areas of molecular nanocarbons, such as research on corannulene, carbon nanorings, graphene nanoribbons, nanographene, warped nanographene and crossdimensional molecular carbons, have undergone tremendous development, leading to important innovations in material science. ${ }^{1-5}$ Chirality is a fascinating geometric property of molecules that are nonsuperimposable on their mirror images. Recently, chiral molecular nanocarbons have attracted considerable interest due to their great potential applications in chiral catalysis, nanotechnology and organic electronics as a result of their novel photophysical, electronic, and supramolecular properties. ${ }^{6}$ For example, we recently reported a chiral molecular nanocarbon named corannurylene pentapetalae, which exhibits a unique honeycomb lattice and nearly isotropic charge transport along six crystal planes. ${ }^{7}$

Helicenes are polycyclic aromatics with screw-shaped skeletons formed from ortho-fused benzene or other aromatic rings. ${ }^{8}$ To endow nanographene with chirality, some chemists successfully introduced helicenes into the structure to obtain novel chiral molecular nanocarbons. ${ }^{9}$ For instance, the synthesis and characterization of perylene diimide-embedded double [8]helicenes and double [6]helicenes were reported recently by us and Nuckolls' group. ${ }^{10}$ Chiral nanographene propellers featuring quintuple [6]helicenes, hexapole [7]helicenes and [9]helicenes were also synthesized by our group and Wang's group. ${ }^{7,11}$ Although great progress has been realized in research

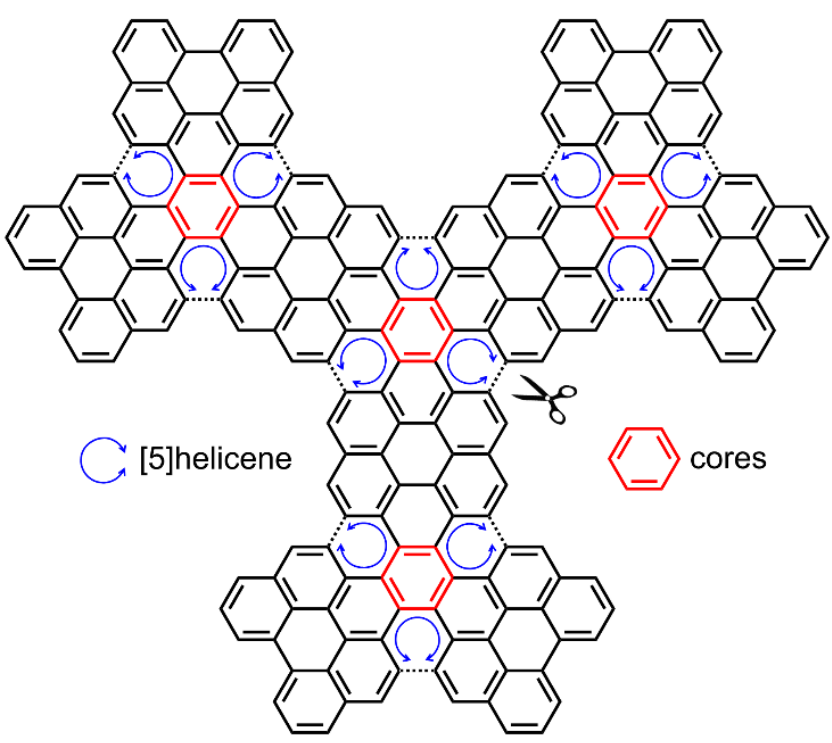

Figure 1. Molecular nanocarbon $\mathrm{C}_{204}$ featuring quad-core twelvefold [5]helicenes.

on chiral molecular nanocarbons containing multiple helicenes, controlling stereoselectivity in chiral molecular nanocarbons is still a major challenge in chemical research, especially for structures with high numbers of multiple helicene moieties.

We recently proposed a strategy for introducing two or more compact helicene cores into nanographene, which could be 
used to add helicene moieties that endow a molecular nanocarbon with chirality and an unusual conformation. However, controlling the stereoselectivity of the topology of a structure containing two or more helicene cores is the first issue to consider. In our previous work, as a new attempt at such stereochemical control, we designed and obtained a dual-core nanocarbon imides featuring sixfold [5]helicenes. ${ }^{12}$ It was encouraging that among the 28 possible stereoisomers, which included 14 pairs of enantiomers, only one pair of enantiomers with high symmetry $((3 P, 3 P)+(3 M, 3 M)$ enantiomers $)$ was observed. However, the stereoselectivity of larger molecular nanocarbons with more helicene cores remains an attractive but challenging goal.

As shown in Figure 1, when the twelve $\mathrm{C}-\mathrm{C}$ bonds of nanographene containing 204 conjugated carbon atoms $\left(\mathrm{C}_{204}\right)$ were sheared off, a novel molecular nanocarbon featuring quad-core twelvefold [5]helicenes could be obtained. Because of the existence of twelvefold [5]helicenes, there are, in theory, more than one hundred stereoisomers. Herein, we realized the stereoselective synthesis of molecular nanocarbon $\mathrm{C}_{204}$ by introducing precisely positioned imide groups. Molecular nanocarbon imides 7 composed of a nanocarbon $\mathrm{C}_{204}$ skeleton and eighteen imide groups was successfully synthesized via an inside-out ring closing strategy of repeated Suzuki-Miyaura coupling for C-C bond formation and photocyclic aromatization. The NMR spectra demonstrated that molecular nanocarbon imides 7 has a highly symmetric stereostructure $\left(D_{3}\right.$ symmetry). A designed ring closing experiment further verified that the structure was more likely to be $7 \mathrm{~A}((3 \mathrm{M}, 3 \mathrm{M}, 3 \mathrm{M}, 3 \mathrm{M})+(3 \mathrm{P}, 3 \mathrm{P}, 3 \mathrm{P}, 3 \mathrm{P})$ enantiomers) instead of $7 \mathrm{~B}((3 \mathrm{M}, 3 \mathrm{M}, 3 \mathrm{M}, 3 P)+(3 P, 3 P, 3 P, 3 \mathrm{M})$ enantiomers). Despite the large size of the nanocarbon $\mathrm{C}_{204}$ skeleton containing twelvefold [5]helicenes, the enantiomers of 7A were successfully separated by chiral HPLC, and the chiroptical properties were investigated by CD spectroscopy.

\section{RESULTS AND DISCUSSION}

Synthesis. The synthetic routes to the molecular nanocarbon imides 7 are shown in Scheme 1. To control the stereostructure of the target nanocarbon imides 7 , we initially chose threebladed triperylene hexaimides (TPH) as a building block that has a $D_{3}$-symmetric stereostructure. ${ }^{13}$ As shown in route $A$, monobromo-TPH 1 was obtained by bromination of TPH in chloroform under reflux for $12 \mathrm{~h}$. Compound 2 was synthesized via a Suzuki coupling reaction between 1,3,5-benzenetriboronic acid tris(pinacol) ester and monobromo-TPH 1 using $\mathrm{Pd}(\mathrm{dppf}) \mathrm{Cl}_{2}$ as the catalyst. Unfortunately, when compound 2 was dissolved in toluene containing a catalytic amount of $\mathrm{I}_{2}$ and irradiated, target product 7 was not observed. Next, we tested other aromatization conditions, as shown in Table S1, but the target product was still not obtained. We speculated that the reactivity and stereostructure of the building block are very important for the construction of nanocarbon imides 7 . Then, we designed the inside-out ring closing strategy as shown in Route B. Monobromo-PDI 3 was obtained according to a known procedure. ${ }^{14}$ We reported a synthetic method for BpinPDI. ${ }^{12}$ Compound 4 was synthesized via Suzuki coupling between 3,5-dichlorophenylboronic acid and monobromo-PDI 3, followed by photocyclization and bromination. Hexachlorinated TPH derivative 5 was acquired via Suzuki coupling between compound 4 and 1,3,5-benzenetriboronic acid tris(pinacol) ester followed by irradiation. Subsequently, compound 6 was obtained in $30 \%$ yield via a sixfold Suzuki-Miyaura crosscoupling reaction between hexachlorinated TPH derivative 5 and Bpin-PDI using $\mathrm{Pd}\left(\mathrm{PPh}_{3}\right)_{4}$ as the catalyst and $\mathrm{K}_{3} \mathrm{PO}_{4}$ as the base. Notably, compound 4 was produced as a mixture of isomers in a ratio of approximately $2: 1$, which can be verified by its ${ }^{1} \mathrm{H}$ NMR data (see the ESI). Therefore, compounds 5 and 6 are also produced as mixtures of isomers, but this does not affect the construction of molecular nanocarbon imides 7 . After compound 6 was dissolved in toluene containing a catalytic amount of $\mathrm{I}_{2}$ and irradiated with a mercury lamp for 5 days at room temperature, molecular nanocarbon imides 7 was obtained in 30\% yield. The molecular nanocarbon imides 7, which have branched alkyl chains, and the related synthetic intermediates have good solubility in common organic solvents and were fully characterized by their ${ }^{1} \mathrm{H}$ and ${ }^{13} \mathrm{C}$ NMR spectra and high-resolution mass spectra.

Stereostructures. The ${ }^{1} \mathrm{H}$ NMR spectrum of the molecular nanocarbon imides 7 (Figure S1) revealed that the stereostructure has $D_{3}$ symmetry. The assignments of $\mathrm{H}_{1}$ to $\mathrm{H}_{6}$ in the skeleton were determined from ${ }^{1} \mathrm{H}-{ }^{1} \mathrm{H}$ COSY, HMBC and ROESY NMR spectra (Figures S2-S6). In the ${ }^{1} \mathrm{H}-{ }^{1} \mathrm{H}$ COSY spectrum in Figure S2, the resonance signals at 9.20 and 9.48 ppm show a strong coupling effect, and there is no long-range coupling between the doublet signal at $9.48 \mathrm{ppm}$ and the carbonyl carbon in the HMBC spectrum in Figure S3. Therefore, the doublet signal at $9.48 \mathrm{ppm}$ corresponds to $\mathrm{H}_{2}$ in the bay region, and the triplet signal at $9.20 \mathrm{ppm}$ corresponds to $\mathrm{H}_{1}$. Based on the similarity of TPH with compound $7, \mathrm{C}_{7}, \mathrm{C}_{8}$ and $\mathrm{C}_{9}$ in compound 7 should be at a position similar to that of $\mathrm{C}_{7}$, in $\mathrm{TPH}$, producing a signal at $127.19 \mathrm{ppm}$ in the HMBC spectrum (Figure S4). As shown in Figure S5, the two protons at 9.52 and $9.72 \mathrm{ppm}$ couple with the carbon at $127.27 \mathrm{ppm}$, and the carbon shows no coupling with $\mathrm{H}_{1}$ in the $\mathrm{HMBC}$ spectrum of compound 7 . Therefore, the two protons are assigned as $\mathrm{H}_{5}$ and $\mathrm{H}_{6}$. The ROESY spectrum in Figure S6 provides further critical evidence confirming these assignments. There is an obvious nuclear Overhauser effect between the protons at 9.72 and 10.15 ppm due to the close spatial distance between $\mathrm{H}_{4}$ and $\mathrm{H}_{5}$ in the [5]helicene. Consequently, the resonance signal at 9.72 ppm corresponds to $\mathrm{H}_{5}$, the signals at 10.15 and $9.52 \mathrm{ppm}$ correspond to $\mathrm{H}_{4}$ and $\mathrm{H}_{6}$, and the signal at $10.37 \mathrm{ppm}$ is attributed to $\mathrm{H}_{3}$.

As shown in Figure 2, the molecular nanocarbon imides 7 with $D_{3}$ symmetry has two pairs of possible stereoisomers: $7 \mathrm{~A}$ $((3 \mathrm{M}, 3 \mathrm{M}, 3 \mathrm{M}, 3 \mathrm{M})+(3 P, 3 P, 3 P, 3 P)$ enantiomers $)$ and $7 \mathrm{~B}$ $((3 \mathrm{M}, 3 \mathrm{M}, 3 \mathrm{M}, 3 \mathrm{P})+(3 P, 3 P, 3 P, 3 \mathrm{M})$ enantiomers). The energies of the two isomers without branched alkyl chains at the imide groups were calculated to have almost the same values and are shown in Table S2. To further confirm the configuration of compound 7 and probe the induction effect of the internal TPH core on the stereoselectivity of the external TPH moieties (Figure S7) in the inside-out ring closing strategy, we designed a confirmatory experiment, as shown in Scheme S1. Instead of hexachlorinated TPH derivative 5, dichlorinated TPH derivative 10 was synthesized under similar conditions which contained a TPH core and two chlorine atoms to construct one of the three external TPH moieties. Compound 11 was obtained via Suzuki coupling between dechlorinated TPH derivative 10 and Bpin-PDI followed by irradiation with a mercury lamp. 

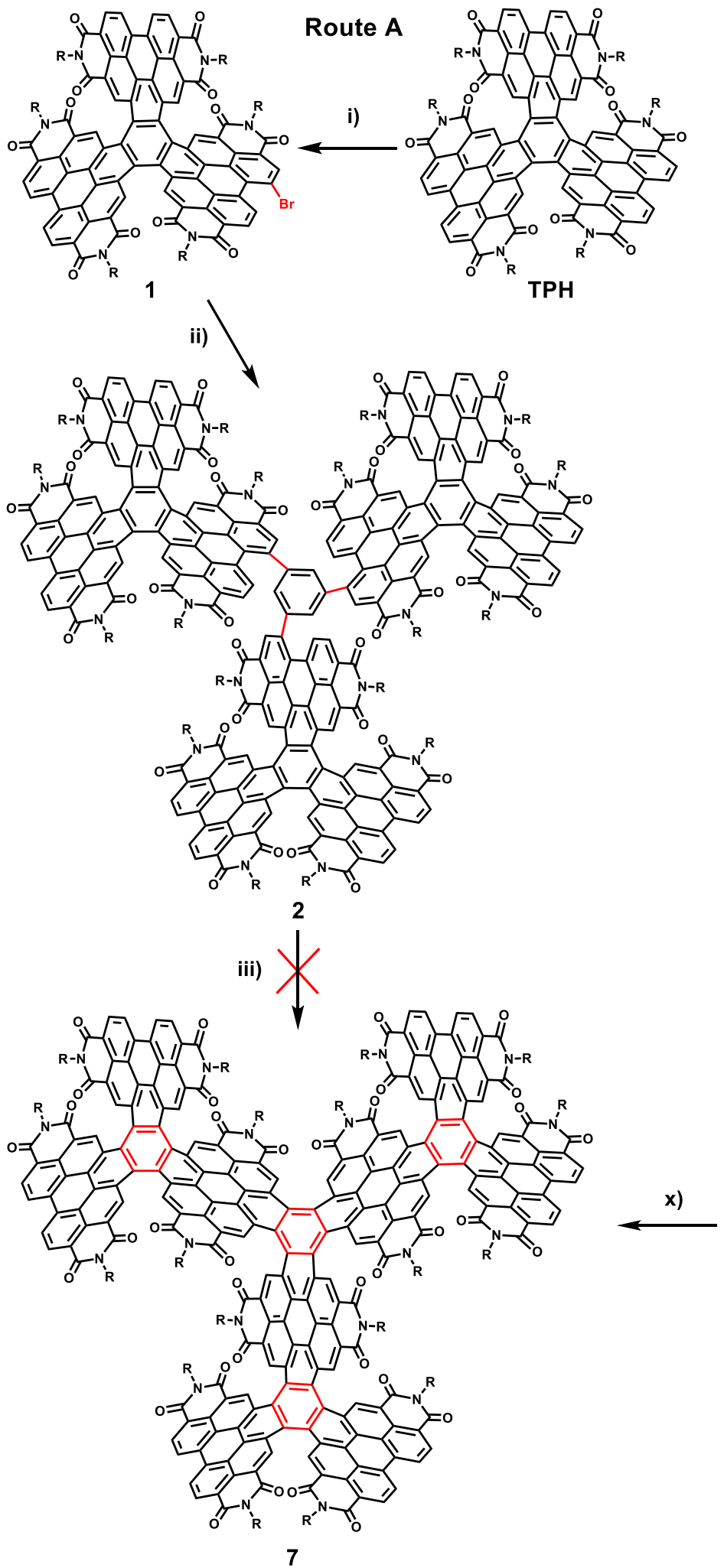
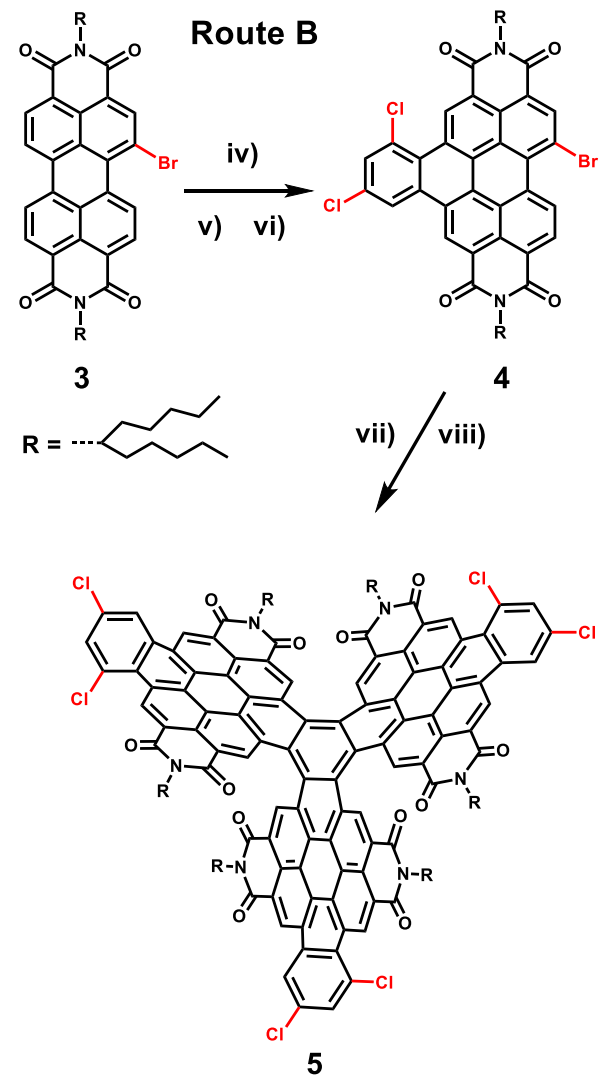

ix)
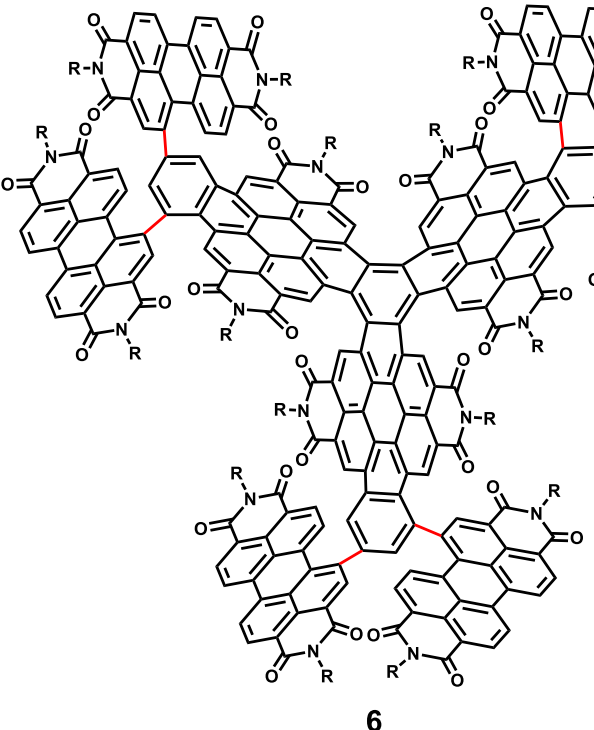

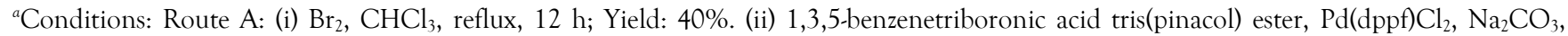
THF $/ \mathrm{H}_{2} \mathrm{O}$, reflux, 12 h; Yield: $30 \%$. (iii) $h v, \mathrm{I}_{2}$, toluene, $25^{\circ} \mathrm{C}, 120$ h; Yield: $0 \%$. Route B: (iv) 3,5-dichlorophenylboronic acid, $\mathrm{Pd}(\mathrm{dppf}) \mathrm{Cl}_{2}$, $\mathrm{K}_{2} \mathrm{HPO}_{4}, \mathrm{THF} / \mathrm{H}_{2} \mathrm{O}, 25^{\circ} \mathrm{C}, 24 \mathrm{~h}$; Yield: 90\%. (v) $\mathrm{hv}, \mathrm{I}_{2}$, toluene, $25^{\circ} \mathrm{C}, 24 \mathrm{~h}$; Yield: $90 \%$. (vi) $\mathrm{Br}_{2}, \mathrm{CHCl}_{3}, 70{ }^{\circ} \mathrm{C}, 12$ h; Yield: $90 \%$. (vii) 1,3,5-benzenetriboronic acid tris(pinacol) ester, $\mathrm{Pd}(\mathrm{dppf}) \mathrm{Cl}_{2}, \mathrm{KOAc}, \mathrm{THF} / \mathrm{H}_{2} \mathrm{O}, 25^{\circ} \mathrm{C}, 12 \mathrm{~h}$; Yield: $70 \%$. (viii) hv, $\mathrm{I}_{2}$, toluene, $25^{\circ} \mathrm{C}, 72 \mathrm{~h}$; Yield: $60 \%$. (ix) Bpin-PDI, $\mathrm{Pd}\left(\mathrm{PPh}_{3}\right)_{4}, \mathrm{~K}_{3} \mathrm{PO}_{4}$, toluene/ $\mathrm{H}_{2} \mathrm{O}, 90^{\circ} \mathrm{C}, 72 \mathrm{~h}$; Yield: $30 \%$. (x): $h v, \mathrm{I}_{2}$, toluene, $25^{\circ} \mathrm{C}, 120$ h; Yield: $30 \%$. 


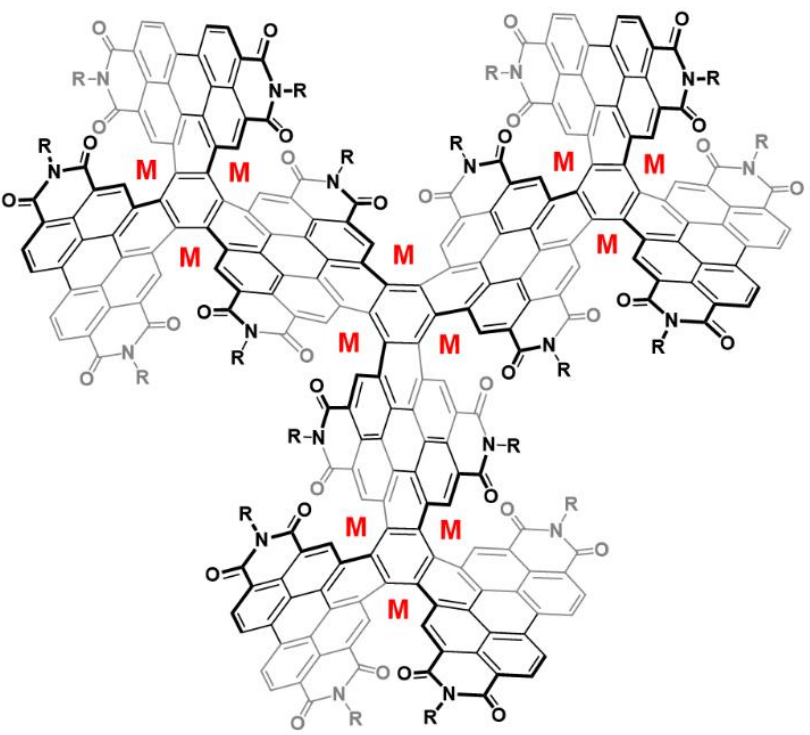

$7 \mathrm{~A}$

$(3 M, 3 M, 3 M, 3 M)+(3 P, 3 P, 3 P, 3 P)$ enantiomers

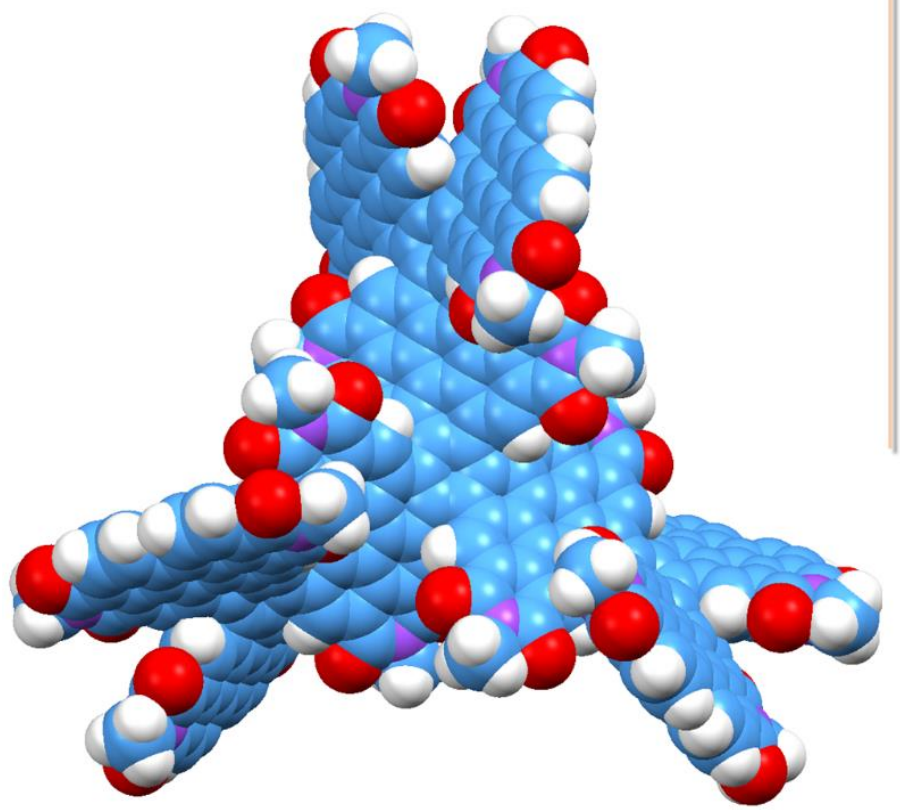

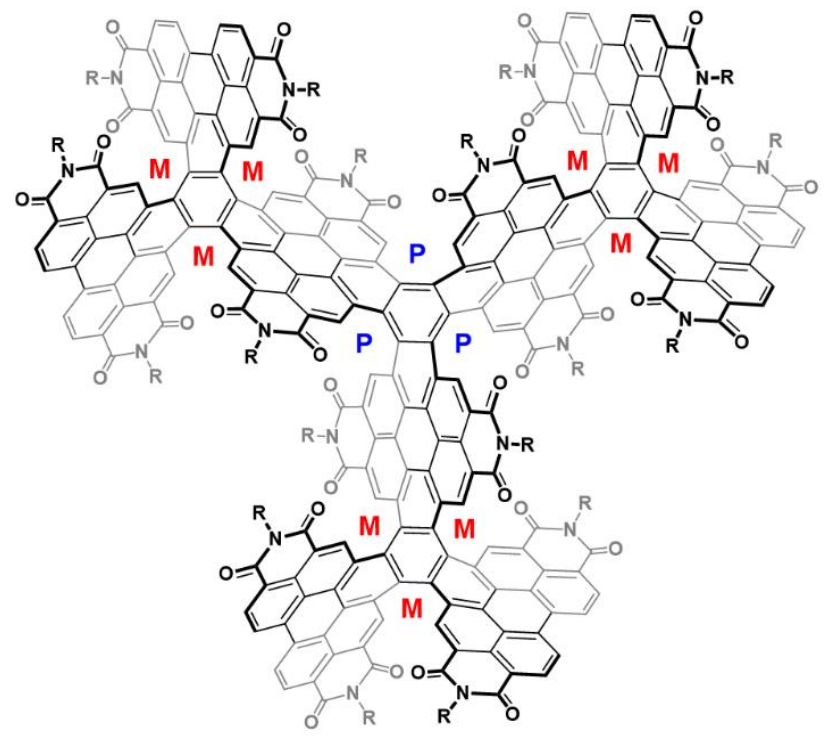

7B

$(3 M, 3 M, 3 M, 3 P)+(3 P, 3 P, 3 P, 3 M)$ enantiomers

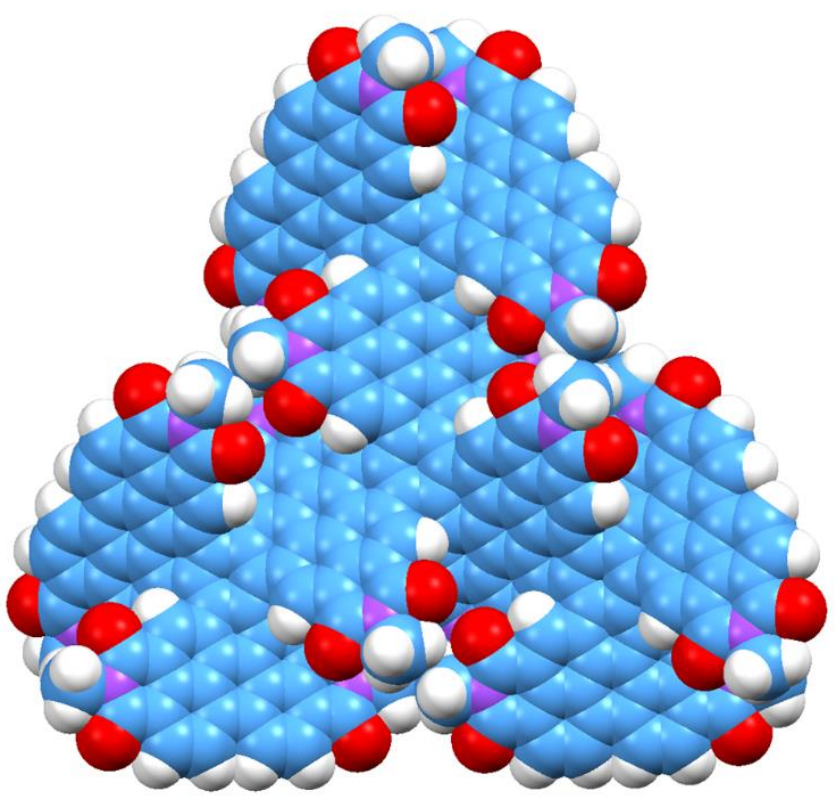

Figure 2. Stereoisomers of $D_{3}$-symmetric chiral molecular nanocarbon imides $7 \mathrm{~A}((3 \mathrm{M}, 3 \mathrm{M}, 3 \mathrm{M}, 3 \mathrm{M})+(3 \mathrm{P}, 3 \mathrm{P}, 3 \mathrm{P}, 3 \mathrm{P})$ enantiomers $)$ and $7 \mathrm{~B}$ $((3 \mathrm{M}, 3 \mathrm{M}, 3 \mathrm{M}, 3 \mathrm{P})+(3 \mathrm{P}, 3 \mathrm{P}, 3 \mathrm{P}, 3 \mathrm{M})$ enantiomers) and corresponding optimized structures based on B3LYP/6-31G*. (The branched alkyl chains at the imide groups are omitted for clarity).

We recently reported compound 11 , which features dual-core sixfold [5]helicenes and is present as $(3 \mathrm{M}, 3 \mathrm{M})+(3 P, 3 P)$ enantiomers with $D_{2}$ symmetry. Comparison of the ${ }^{1} \mathrm{H}$ NMR spectra, shown in Figure S8, it was confirmed that the $D_{3}$-symmetric molecular nanocarbon imides 7 is more likely the conformation of $7 \mathrm{~A}$ instead of $7 \mathrm{~B}$. The optimized structures of $7 \mathrm{~A}$ and $7 \mathrm{~B}$ are also shown in Figure 2, from which it can be seen that in the topology of $7 \mathbf{B}$, the imide groups have large steric hindrance during the internal and external PDI subunits.

Optical and Electronic Properties. To investigate the variation in the electronic properties of molecular nanocarbon imides 7, UV/Vis absorption measurement was performed in a $\mathrm{CHCl}_{3}$ solution and compared with the properties of TPH. As shown in Figure 3a, molecular nanocarbon imides 7 exhibits intense absorption in the entire 300 to $600 \mathrm{~nm}$ region, with the lowest-energy maximum at $595 \mathrm{~nm}$. There are two main bands for compound 7, with the highest molar extinction coefficient of $277500 \mathrm{M}^{-1} \mathrm{~cm}^{-1}$ at $384 \mathrm{~nm}$ in the first band and $291200 \mathrm{M}^{-}$ ${ }^{1} \mathrm{~cm}^{-1}$ at $538 \mathrm{~nm}$ in the second band. Figure S9 shows that the shape of the absorption curve of compound 7 is very similar to that of TPH; however, the overall molar extinction coefficient based on the two bands is approximately two times that of TPH, with the lowest-energy maximum of 7 bathochromically shifted by $79 \mathrm{~nm}$. To the best of our knowledge, the molar extinction coefficient of compound 7 is highest in the visible region, which means that it is a great light-capturing material for the visible region and has potential applications in various optoelectronic devices. TDDFT calculations with the B3LYP functional and the $6-31 G^{*}$ basis set predicted that the lowest energy 
peak consists of several individual excitations with an envelope peaking at $597 \mathrm{~nm}$. The predominant contributions to this peak are the transitions from HOMO- 1 and HOMO-2 to the $\mathrm{LUMO}+1$ and LUMO+2 (Table S3). In line with the experimental data, the theoretical spectrum shows a prominent peak at $540 \mathrm{~nm}$, arising from transitions from the 5 highest occupied to the 8 lowest unoccupied orbitals. The fluorescence spectrum of compound 7 is shown in Figure $3 \mathrm{a}$ and has an emission maximum at $620 \mathrm{~nm}$. The small Stokes shift $(25 \mathrm{~nm})$ between the absorption and emission bands can be attributed to the rigid backbone containing multiple [5]helicenes. The fluorescence quantum yield of compound 7 in chloroform is $15 \%$. The electrochemical property of compound 7 was investigated using cyclic voltammetry in a $\mathrm{CH}_{2} \mathrm{Cl}_{2}$ solution. As shown in Figure $\mathrm{S} 10$, the LUMO level of compound 7 was determined from the onset reduction potential to be $-3.82 \mathrm{eV}$, which is the same as that $(-3.83 \mathrm{eV})$ of TPH, implying that 7 is a potential acceptor for use in organic solar cells. The energy gap $E_{g}$ estimated from the edge of the absorption spectrum is $2.0 \mathrm{eV}$. Thus, the $\mathrm{HOMO}$ level of compound 7 is calculated to be $-5.82 \mathrm{eV}$.

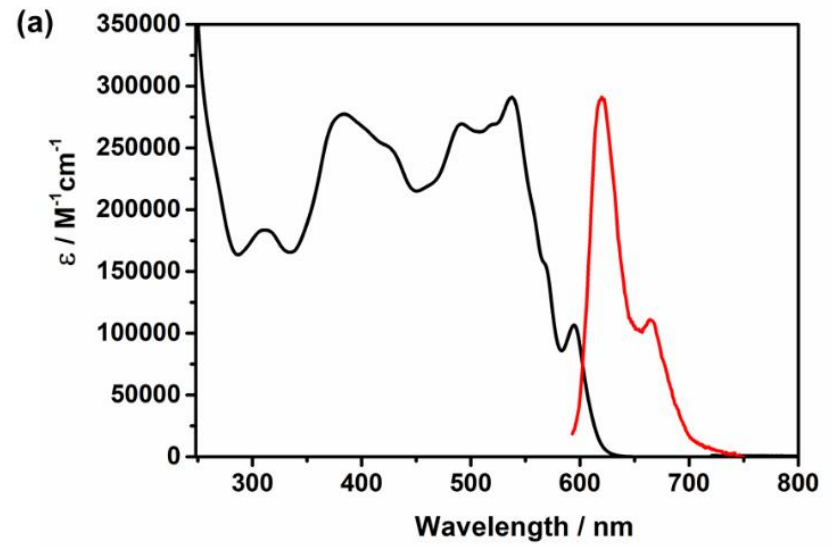

(b)

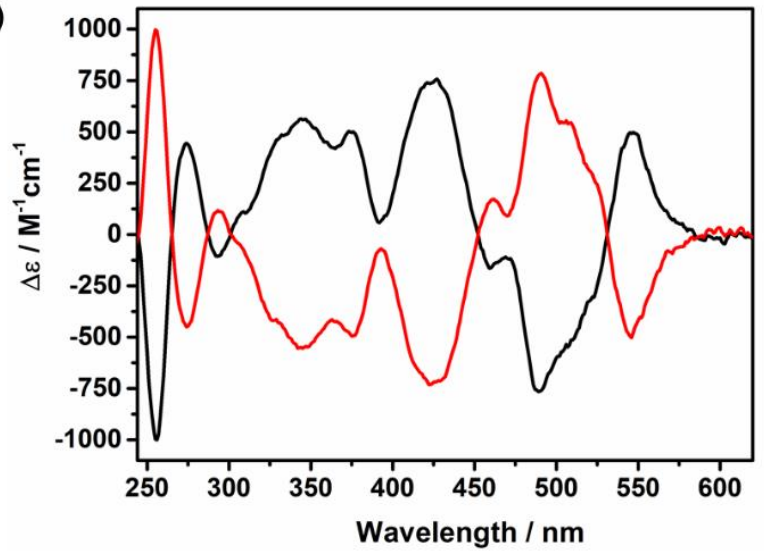

Figure 3. (a) UV/Vis absorbance (black, $1 \times 10^{-5} \mathrm{M}$ ) and fluorescence (red, $\lambda_{\mathrm{ex}}=583 \mathrm{~nm}$ ) spectra of molecular nanocarbon imides 7 in $\mathrm{CHCl}_{3}$ at room temperature. (b) $\mathrm{CD}$ spectra of compound 7 $((+)-7 \mathrm{~A}$, red, (3P,3P,3P,3P); (-)-7A, black, $(3 \mathrm{M}, 3 \mathrm{M}, 3 \mathrm{M}, 3 \mathrm{M}))$ in $\mathrm{CHCl}_{3}\left(1 \times 10^{-6} \mathrm{M}, 1 \mathrm{~cm}\right.$ path length $)$.

Chiroptical Properties. Even though the nanocarbon $\mathrm{C}_{204}$ skeleton was large, the chiroptical properties of the molecular nanocarbon imides 7 were investigated by circular dichroism (CD) spectroscopy in $\mathrm{CHCl}_{3}$; TPH was analyzed for comparison. The enantiomers $(3 \mathrm{M}, 3 \mathrm{M}, 3 \mathrm{M}, 3 \mathrm{M})+(3 \mathrm{P}, 3 \mathrm{P}, 3 \mathrm{P}, 3 \mathrm{P})$ of compound $7 \mathrm{~A}$ and the enantiomers $(3 \mathrm{M})+(3 \mathrm{P})$ of TPH were separated us- ing chiral high-performance liquid chromatography (HPLC) (Figure S11). As shown in Figure 3b, the mirror-imaged CD spectrum shows a complicated pattern of strong peaks in the $\mathrm{UV} / \mathrm{V}$ is region with a $\Delta \varepsilon$ value in the range of $\pm 1000 \mathrm{M}^{-1} \mathrm{~cm}^{-1}$. In the visible region, the first HPLC fraction $\left(t_{R}=3.06 \mathrm{~min}\right)$ demonstrated two impressive positive Cotton effects at $427 \mathrm{~nm}$ $\left(\Delta \varepsilon=757 \mathrm{M}^{-1} \mathrm{~cm}^{-1}, g_{\text {abs }}=\Delta \varepsilon / \varepsilon=3.0 \times 10^{-3}\right)$ and at the lowest energy transition of $547 \mathrm{~nm}\left(\Delta \varepsilon=498 \mathrm{M}^{-1} \mathrm{~cm}^{-1}, g_{\text {abs }}=\Delta \varepsilon / \varepsilon=1.9 \times 10^{-3}\right)$, and one negative Cotton effect at $489 \mathrm{~nm}\left(|\Delta \varepsilon|=766 \mathrm{M}^{-1} \mathrm{~cm}^{-1}\right.$, $\left.g_{\text {abs }}=|\Delta \varepsilon| / \varepsilon=2.9 \times 10^{-3}\right)$. The second eluted enantiomer $\left(t_{R}=3.96\right.$ $\mathrm{min}$ ) produced a spectrum that was a mirror image of the spectrum of the first fraction. Moreover, the distribution and intensity of the CD signals from compound 7 and TPH were compared. As shown in Figure S12, the intensity of the peak at 256 $\mathrm{nm}$ produced by compound 7 is approximately 6 times that produced by TPH, which is related to the cumulative increase in the number of [5]helicene moieties with full-P or full-M configurations. According to the TD-DFT calculations shown in Figure S13, the second eluted enantiomer was assigned to the $(3 P, 3 P, 3 P, 3 P)$-configuration $((+)-7 \mathrm{~A}$, red line in Figure $3 \mathrm{~b})$. Inevitably, the first eluted enantiomer that produced a mirrorimage spectra to that of $(+)-7 \mathrm{~A}$ was assigned to the $(3 \mathrm{M}, 3 \mathrm{M}, 3 \mathrm{M}, 3 \mathrm{M})$-configuration $((-)-7 \mathrm{~A}$, black line in Figure $3 b)$.

\section{CONCLUSIONS}

In summary, we achieved stereoselective synthesis of highly symmetric chiral molecular nanocarbon imides featuring quadcore twelvefold [5]helicenes by introducing eighteen imide groups into the $\mathrm{C}_{204}$ skeleton and adopting an inside-out ring closing strategy. A particular advantage of introducing eighteen imide groups into the $\mathrm{C}_{204}$ skeleton is the enhanced steric hindrance effect from the multiple helicenes, in addition to the additional modification sites. The large steric hindrance effect from the overlapping imide groups helps prevent inversion of the configuration. The inside-out ring closing strategy enables configurational controllability via the induction effect of the internal TPH core on the stereostructure of the external TPH moieties. Moreover, the symmetry of the building block core is very important to the stereostructure of the final molecular nanocarbon. A highly symmetric building block core is often able to construct molecular nanocarbons with high symmetry. This work not only provides effective strategies for constructing highly symmetric molecular nanocarbons featuring multiple helicene moieties, but also provides a feasible way to directly produce chiral molecular nanocarbons via the induction effect of chiral seeds. Further exploration of the direct construction of chiral molecular nanocarbons starting from monochiral building block with a TPH core is ongoing in our laboratory.

\section{ASSOCIATED CONTENT}

\section{Supporting Information}

More detailed experimental procedures, characterizations, theoretical calculations, and supplementary spectra and figures (PDF)

\section{AUTHOR INFORMATION}

\section{Corresponding Authors}

*liuguogang@ecust.edu.cn

*yanli_chem@buaa.edu.cn 
*wangzhaohui@mail.tsinghua.edu.cn

\section{Notes}

The authors declare no competing financial interest.

\section{ACKNOWLEDGMENT}

This work was financially supported by the National Natural Science Foundation of China (NSFC) (No. 52022099, 21790361), the National Postdoctoral Program for Innovative Talents (BX20200128), Shanghai Municipal Science and Technology Major Project (grant 2018SHZDZX03).

\section{REFERENCES}

(1) (a) Wu, Y.-T.; Siegel, J. S. Aromatic Molecular-Bowl Hydrocarbons: Synthetic Derivatives, Their Structures, and Physical Properties. Chem. Rev. 2006, 106, 4843-4867. (b) Tsefrikas, V. M.; Scott, L. T. Geodesic Polyarenes by Flash Vacuum Pyrolysis. Chem. Rev. 2006, 106, 4868-4884. (c) Zoppi, L.; Martin-Samos, L.; Baldridge, K. K. StructureProperty Relationships of Curved Aromatic Materials from First Principles. Acc. Chem. Res. 2014, 47, 3310-3320. (d) Ronson, T. K.; Wang, Y.; Baldridge, K.; Siegel, J. S.; Nitschke, J. R. An S10-Symmetric 5-Fold Interlocked [2]Catenane. J. Am. Chem. Soc. 2020, 142, 10267-10272.

(2) for selected examples, see (a) Golder, M. R.; Jasti, R. Syntheses of the Smallest Carbon Nanohoops and the Emergence of Unique Physical Phenomena. Acc. Chem. Res. 2015, 48, 557-566. (b) Segawa, Y.; Levine, D. R.; Itami, K. Topologically Unique Molecular Nanocarbons. Acc. Chem. Res. 2019, 52, 2760-2767. (c) Jasti, R.; Bhattacharjee, J.; Neaton, J. B.; Bertozzi, C. R. Synthesis, Characterization, and Theory of [9]-, [12]-, and [18]Cycloparaphenylene: Carbon Nanohoop Structures. J. Am. Chem. Soc. 2008, 130, 17646-17647. (d) Yamago, S.; Watanabe, Y.; Iwamoto, T. Synthesis of [8]Cycloparaphenylene from a Square-Shaped Tetranuclear Platinum Complex. Angew. Chem. Int. Ed. 2010, 49, 757-759. (e) Senthilkumar, K.; Kondratowicz, M.; Lis, T.; Chmielewski, P. J.; Cybińska, J.; Zafra, J. L.; Casado, J.; Vives, T.; Crassous, J.; Favereau, L.; Stępień, M. Lemniscular [16]Cycloparaphenylene: A Radially Conjugated Figure-Eight Aromatic Molecule. J. Am. Chem. Soc. 2019, 141, 7421-7427.

(3) (a) Yang, X.; Dou, X.; Rouhanipour, A.; Zhi, L.; Räder, H. J.; Müllen, K. Two-Dimensional Graphene Nanoribbons. J. Am. Chem. Soc. 2008, 130, 4216-4217. (b) Li, Y.; Gao, J.; Di Motta, S.; Negri, F.; Wang, Z. Tri-N-annulated Hexarylene: An Approach to Well-Defined Graphene Nanoribbons with Large Dipoles. J. Am. Chem. Soc. 2010, 132, 4208-4213. (c) Cai, J.; Ruffieux, P.; Jaafar, R.; Bieri, M.; Braun, T.; Blankenburg, S.; Muoth, M.; Seitsonen, A. P.; Saleh, M.; Feng, X.; Müllen, K.; Fasel, R. Atomically Precise Bottom-Up Fabrication of Graphene Nanoribbons. Nature 2010, 466, 470-473. (d) Liu, Z.; Chen, Z.; Wang, C.; Wang, H. I.; Wuttke, M.; Wang, X.Y.; Bonn, M.; Chi, L.; Narita, A.; Müllen, K. Bottom-Up, On-Surface-Synthesized Armchair Graphene Nanoribbons for Ultra-High-Power Micro-Supercapacitors. J. Am. Chem. Soc. 2020, 142, 17881-17886. (e) Yano, Y.; Wang, F.; Mitoma, N.; Miyauchi, Y.; Ito, H.; Itami, K. Step-Growth Annulative $\pi$ Extension Polymerization for Synthesis of Cove-Type Graphene Nanoribbons. J. Am. Chem. Soc. 2020, 142, 1686-1691.

(4) (a) Narita, A.; Wang, X.Y.; Feng, X.; Müllen, K. New Advances in Nanographene Chemistry. Chem. Soc. Rev. 2015, 44, 6616-6643. (b) Stępień, M.; Gońka, E.; Żyła, M.; Sprutta, N. Heterocyclic Nanographenes and Other Polycyclic Heteroaromatic Compounds: Synthetic Routes, Properties, and Applications. Chem. Rev. 2017, 117, 3479-3716. (c) Wang, X.-Y.; Yao, X.; Narita, A.; Müllen, K. Heteroatom-Doped Nanographenes with Structural Precision. Acc. Chem. Res. 2019, 52, 2491-2505. (d) Seifert, S.; Shoyama, K.; Schmidt, D.; Würthner, F. An Electron-Poor $\mathrm{C}_{64}$ Nanographene by Palladium-Catalyzed Cascade C-C Bond Formation: One-Pot Synthesis and Single-Crystal Structure Analysis. Angew. Chem. Int. Ed. 2016, 55, 6390-6395. (e) Gu, Y.; MuñozMármol, R.; Wu, S.; Han, Y.; Ni, Y.; Díaz-García, M. A.; Casado, J.;
Wu, J. Cove-Edged Nanographenes with Localized Double Bonds. Angew. Chem. Int. Ed. 2020, 59, 8113-8117. (f) Ajayakumar, M. R.; Fu, Y.; Ma, J.; Hennersdorf, F.; Komber, H.; Weigand, J. J.; Alfonsov, A.; Popov, A. A.; Berger, R.; Liu, J.; Müllen, K.; Feng, X. Toward Full Zigzag-Edged Nanographenes: peri-Tetracene and Its Corresponding Circumanthracene. J. Am. Chem. Soc. 2018, 140, 6240-6244.

(5) (a) Jiang, W.; Li, Y.; Wang, Z. Tailor-Made Rylene Arrays for High Performance n-Channel Semiconductors. Acc. Chem. Res. 2014, 47, 3135-3147. (b) Pun, S. H.; Miao, Q. Toward Negatively Curved Carbons. Acc. Chem. Res. 2018, 51, 1630-1642. (c) Kawasumi, K.; Zhang, Q.; Segawa,Y.; Scott, L. T.; Itami, K. A Grossly Warped Nanographene and the Consequences of Multiple Odd-Membered-Ring Dedects. Nat. Chem. 2013, 5, 739-744. (d) Qiu, Z.; Asako, S.; Hu, Y.; Ju, C.-W.; Liu, T.; Rondin, L.; Schollmeyer, D.; Lauret, J.S.; Müllen, K.; Narita, A. Negatively Curved Nanographene with Heptagonal and [5]Helicene Units. J. Am. Chem. Soc. 2020, 142, 14814-14819. (e) Shoyama, K.; Würthner, F. Synthesis of a Carbon Nanocone by Cascade Annulation. J. Am. Chem. Soc. 2019, 141, 13008-13012. (f) UrietaMora, J.; Krug, M.; Alex, W.; Perles, J.; Fernández, I.; Molina-Ontoria, A.; Guldi, D. M.; Martín, N. Homo and Hetero Molecular 3D Nanographenes Employing a Cyclooctatetraene Scaffold. J. Am. Chem. Soc. 2020, 142, 4162-4172. (g) Feng, J.; Wu, Y.; Yu, Q.; Liu, Y.; Jiang, W.; Wang, D.; Wang, Z. Fuller-Rylenes: Cross-Dimensional Molecular Carbons. CCS Chem. 2020, 2, 271-279.

(6) (a) Fernández-García, J. M.; Evans, P. J.; Filippone, S.; Herranz, M. Á.; Martín, N. Chiral Molecular Carbon Nanostructures. Acc. Chem. Res. 2019, 52, 1565-1574. (b) Thilgen, C.; Diederich, F. Structural Aspects of Fullerene Chemistry-A Journey Through Fullerene Chirality. Chem. Rev. 2006, 106, 5049-5135. (c) Maroto, E. E.; Izquierdo, M.; Reboredo, S.; Marco-Martínez, J.; Filippone, S.; Martín, N. Chiral Fullerenes from Asymmetric Catalysis. Acc. Chem. Res. 2014, 47, 2660 2670. (d) Brandt, J. R.; Salerno, F.; Fuchter, M. J. The Added Value of Small-Molecule Chirality in Technological Applications. Nat. Rev. Chem. 2017, 1, 0045. (e) Kane-Maguire, L. A. P.; Wallace, G. G. Chiral Conducting Polymers. Chem. Soc. Rev. 2010, 39, 2545-2576. (f) Yang, F.; Wang, X.; Zhang, D.; Yang, J.; Luo, D.; Xu, Z.; Wei, J.; Wang, J.-Q.; Xu, Z.; Peng, F.; Li, X.; Li, R.; Li, Y.; Li, M.; Bai, X.; Ding, F.; Li, Y. Chirality-Specific Growth of Single-Walled Carbon Nanotubes on Solid Alloy Catalysts. Nature 2014, 510, 522-524.

(7) (a) Meng, D.; Liu, G.; Xiao, C.; Shi, Y.; Zhang, L.; Jiang, L.; Baldridge, K. K.; Li, Y.; Siegel, J. S.; Wang, Z. Corannurylene Pentapetalae. J. Am. Chem. Soc. 2019, 141, 5402-5408. (b) Chen, S.; Meng, D.; Huang, J.; Liang, N.; Li, Y.; Liu, F.; Yan, H.; Wang, Z. SymmetryInduced Orderly Assembly Achieving High-Performance Perylene Diimide-Based Nonfullerene Organic Solar Cells. CCS Chem. 2021, 3, 78-84.

(8) (a) Stará, I. G.; Starý, I. Helically Chiral Aromatics: The Synthesis of Helicenes by $[2+2+2]$ Cycloisomerization of $\pi$-Electron Systems. Acc. Chem. Res. 2020, 53, 144-158. (b) Dhbaibi, K.; Favereau, L.; Crassous, J. Enantioenriched Helicenes and Helicenoids Containing Main-Group Elements (B, Si, N, P). Chem. Rev. 2019, 119, 8846-8953. (c) Shen, Y.; Chen, C.-F. Helicenes: Synthesis and Applications. Chem. Rev. 2012, 112, 1463-1535. (d) Yang, Y.; da Costa, R. C.; Fuchter, M. J.; Campbell, A. J. Circularly Polarized Light Detection by a Chiral Organic Semiconductor Transistor. Nat. Photonics 2013, 7, 634-638. (e) Hatakeyama, T.; Hashimoto, S.; Oba, T.; Nakamura, M. Azaboradibenzo[6]helicene: Carrier Inversion Induced by Helical Homochirality. J. Am. Chem. Soc. 2012, 134, 19600-19603. (f) Wang, X.-Y.; Wang, X.-C.; Narita, A.; Wagner, M.; Cao, X.Y.; Feng, X.; Müllen, K. Synthesis, Structure, and Chiroptical Properties of a Double [7]heterohelicene. J. Am. Chem. Soc. 2016, 138, 12783-12786.

(9) (a) Ball, M.; Zhong, Y.; Wu, Y.; Schenck, C.; Ng, F.; Steigerwald, M.; Xiao, S.; Nuckolls, C. Contorted Polycyclic Aromatics. Acc. Chem. Res. 2015, 48, 267-276. (b) Navakouski, M.; Zhylitskaya, H.; Chmielewski, P. J.; Lis, T.; Cybińska, J.; Stępień, M. Stereocontrolled Synthesis of Chiral Heteroaromatic Propellers with Small Optical Bandgaps. 
Angew. Chem. Int. Ed. 2019, 58, 4929-4933. (c) Hu, Y.; Paternò, G. M.; Wang, X.Y.; Wang, X.-C.; Guizzardi, M.; Chen, Q.; Schollmeyer, D.; Cao, X.-Y.; Cerullo, G.; Scotognella, F.; Müllen, K.; Narita, A. $\pi$ Extended Pyrene-Fused Double [7]Carbohelicene as a Chiral Polycyclic Aromatic Hydrocarbon. J. Am. Chem. Soc. 2019, 141, 12797-12803. (d) Daigle, M.; Miao, D.; Lucotti, A.; Tommasini, M.; Morin, J.-F. Helically Coiled Graphene Nanoribbons. Angew. Chem. Int. Ed. 2017, 56, 6213. 6217. (e) Kiel, G. R.; Bay, K. L.; Samkian, A. E.; Schuster, N. J.; Lin, J. B.; Handford, R. C.; Nuckolls, C.; Houk, K. N.; Tilley, T. D. Expanded Helicenes as Synthons for Chiral Macrocyclic Nanocarbons. J. Am. Chem. Soc. 2020, 142, 11084-11091. (f) Ma, Z.; Winands, T.; Liang, N.; Meng, D.; Jiang, W.; Doltsinis, N. L.; Wang, Z. A C 2 -Symmetric Triple [5]Helicene based on N-Annulated Triperylene Hexaimide for Chiroptical Electronics. Sci. China Chem. 2020, 63, 208-214.

(10) (a) Liu, B.; Böckmann, M.; Jiang, W.; Doltsinis, N. L.; Wang, Z. Perylene Diimide-Embedded Double [8]Helicenes. J. Am. Chem. Soc. 2020, 142, 7092-7099. (b) Schuster, N. J.; Sánchez, R. H.; Bukharina, D.; Kotov, N. A.; Berova, N.; Ng, F.; Steigerwald, M. L.; Nuckolls, C. A Helicene Nanoribbon with Greatly Amplified Chirality. J. Am. Chem. Soc. 2018, 140, 6235-6239.

(11) (a) Zhu, Y.; Xia, Z.; Cai, Z.; Yuan, Z.; Jiang, N.; Li, T.; Wang, Y.; Guo, X.; Li, Z.; Ma, S.; Zhong, D.; Li, Y.; Wang, J. Synthesis and Characterization of Hexapole [7]Helicene, A Circularly Twisted Chiral Nanographene. J. Am. Chem. Soc. 2018, 140, 4222-4226. (b) Wang, Y.; Yin, Z.; Zhu, Y.; Gu, J.; Li, Y.; Wang, J. Hexapole [9]Helicene. Angew. Chem. Int. Ed. 2019, 58, 587-591.

(12) Liu, G.; Koch, T.; Li, Y.; Doltsinis, N. L.; Wang, Z. Nanographene Imides Featuring Dual-Core Sixfold [5]Helicenes. Angew. Chem. Int. Ed. 2019, 58, 178-183.

(13) Meng, D.; Fu, H.; Xiao, C.; Meng, X.; Winands, T.; Ma, W.; Wei, W.; Fan, B.; Huo, L.; Doltsinis, N. L.; Li, Y.; Sun, Y.; Wang, Z. Three-Bladed Rylene Propellers with Three-Dimensional Network Assembly for Organic Electronics. J. Am. Chem. Soc. 2016, 138, 1018410190.

(14) Rajasingh, P.; Cohen, R.; Shirman, E.; Shimon, L. J. W.; Rybtchinski, B. Selective Bromination of Perylene Diimides under Mild Conditions. J. Org. Chem. 2007, 72, 5973-5979. 
TOC

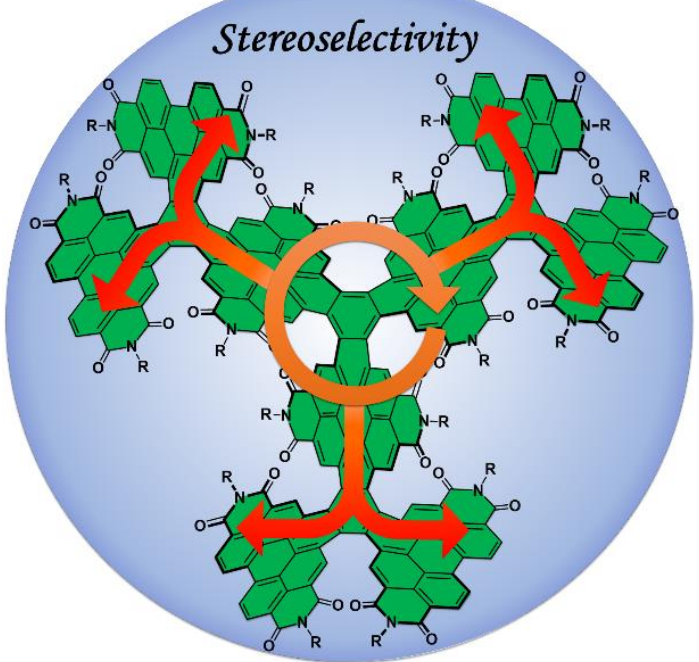

